\title{
A história da pessoa com deficiência e da educação especial em tempos de inclusão
}

\author{
RODRIGUES, Ana Paula Neves ${ }^{1}$ \\ LIMA, Cláudia Araújo de ${ }^{2}$
}

Resumo

O presente artigo teve por objetivo, realizar uma breve exposição acerca da história das pessoas/estudantes com deficiência, para entender os "reflexos" no campo educacional, assim como, levantar a importância trazida através da garantia de Direitos tangentes a essa população, até então, antes esquecida. Atualmente, a Educação Especial na Perspectiva da Educação Inclusiva é respaldada através de leis, documentos internacionais e políticas voltadas à inclusão, que subsidiarão o texto do referido artigo e que respaldam, tanto o acesso como a permanência de estudantes com deficiência. Entender a história das pessoas/estudantes com deficiência, ao longo dos tempos, torna-se valoroso, pois, as lutas e a garantia dos seus direitos "provocam" possibilidades de mudanças para o contexto educacional de uma forma geral. Afinal, TODOS possuem o direito à educação, mediante a qualidade de ensino, que foi por muito tempo, negada à grande parte da população.

Pessoas com Deficiência. Educação Especial. Educação Inclusiva. Direitos Humanos.

\section{Resumen}

El presente artículo tuvo por objetivo, realizar una breve exposición acerca de la historia de las personas/estudiantes con discapacidad, para entender los "reflejos" en el campo educativo, así como, levantar la importancia traída a través de la garantía de derechos tangentes a esa población, hasta entonces, antes olvidada. Actualmente, la Educación Especial en la Perspectiva de la Educación Inclusiva es respaldada a través de leyes, documentos internacionales y políticas orientadas a la inclusión, que subsidiarán el texto del referido artículo y que respaldan tanto el acceso como la permanencia de estudiantes con discapacidad. Entender la historia de las personas / estudiantes con discapacidad, a lo largo de los tiempos, se vuelve valerosa, pues, las luchas y la garantía de sus derechos "provocan" posibilidades de cambios para el contexto educativo de una forma general. Una vez que, TODOS poseen el derecho a la educación, mediante la calidad de enseñanza, que fue de largo, negada a la gran parte de la población.

Personas con discapacidad. Educación Especial. Educación Inclusiva. Derechos Humanos.

\section{Introdução}

O Brasil vem buscando, através de leis, documentos internacionais e políticas voltadas à inclusão, o "reparo" ao atendimento às pessoas ou estudantes com deficiência, que por muito tempo, viveram excluídos da sociedade. Tal afirmação encontra-se presente no documento:

\footnotetext{
${ }^{1}$ Mestranda do Programa de Pós-Graduação em Educação do Campus do Pantanal (CPAN), área de concentração em Educação Social, da Universidade Federal de Mato Grosso do Sul (UFMS). apnevesrodrigues@gmail.com

${ }^{2}$ Professora Drª Adjunta do Programa de Pós-Graduação em Educação do Campus do Pantanal (CPAN), área de concentração em Educação Social, da Universidade Federal de Mato Grosso do Sul (UFMS). claudia.araujolima@gmail.com
} 
O Brasil é um país onde os problemas sociais vêm sendo redimensionados através de programas e incentivos de políticas públicas de inclusão e reparo às violações dos direitos humanos. Ainda o preconceito e as disparidades sociais contribuem para o declínio do cenário humanístico, cultural, político e econômico. Os direitos humanos podem mudar essa realidade, e a educação é o principal viés para essa transformação, por meio da dignidade da pessoa humana. (BRASIL, 2013, p. 44).

Mudanças passam a ocorrer desde a promulgação da Constituição Federal em 1988, onde fica estabelecido que "a educação é um direito de todos e dever do Estado e da família" (art. 205), garantindo em um dos seus princípios a "igualdade de condições para o acesso e permanência na escola" (art.206, I).

De acordo com a LDB 9.394/96, em seu art. 59, a educação especial corresponde aos estudantes com deficiência, transtornos globais do desenvolvimento e altas habilidades ou superdotação.

A respeito da segregação e exclusão de pessoas com deficiência:

A história da atenção à pessoa com necessidades educacionais especiais tem se caracterizado pela segregação, acompanhada pela consequente e gradativa exclusão, sob diferentes argumentos, dependendo do momento histórico focalizado. No decorrer da História da Humanidade foram se diversificando a visão e a compreensão que as diferentes sociedades tinham acerca da deficiência. A forma de pensar e por consequência a forma de agir com relação à deficiência enquanto fenômeno e à pessoa com necessidades educacionais especiais enquanto ser modificaram-se no decorrer do tempo e das condições sócio históricas. (ARANHA, 2005, p. 5).

Lembramos ainda que:

Percorrendo os períodos da história universal, desde os mais remotos tempos, evidenciam-se teorias e práticas sociais segregadoras, inclusive quanto o acesso ao saber. Poucos podiam participar dos espaços sociais nos quais se transmitiam e se criavam conhecimentos. A pedagogia da exclusão tem origens remotas, condizentes com o modo como estão sendo construídas as condições de existência da humanidade em determinado momento histórico. (BRASIL, 2004, p. 322).

Atualmente as pessoas/estudantes com deficiência conquistaram a garantia dos seus direitos, mas por muito tempo, eles foram desprovidos dessa realidade, conforme a citação do presente documento:

Os indivíduos com deficiências, vistos como "doentes" e incapazes, sempre estiveram em situação de maior desvantagem, ocupando, no imaginário coletivo, a posição de alvos da caridade popular e da assistência social, e não de sujeitos de direitos sociais, entre os quais se inclui o direito à 
educação. Ainda hoje, constata-se a dificuldade de aceitação do diferente no seio familiar e social, principalmente do portador de deficiências múltiplas e graves, que na escolarização apresenta dificuldades acentuadas de aprendizagem. (BRASIL, 2004, p. 322).

Compreendendo toda essa trajetória, torna-se importante pesquisar os caminhos que vêm sendo percorridos para o alcance de um sistema educacional realmente inclusivo, sob essa égide, há muito que ser feito ainda. As mudanças propostas pela inclusão de estudantes com deficiência são importantes na garantia de direitos, porém, para a consolidação de um sistema educacional inclusivo, torna-se fundamental o acesso e permanência mediante um ensino de qualidade.

Os termos, "deficiência", "deficiente", "portador de deficiência" e "portador de necessidades especiais" surgiram bem recentemente, já no século $X X$ (ARANHA, 2005, p. 6, grifos da autora). Atualmente a denominação a ser considerada é pessoa com deficiência, relacionando à educação, são utilizados os termos alunos/estudantes com deficiência.

\section{A pessoa com Deficiência em diferentes contextos históricos}

No intuito de elucidar a importância da Educação Especial no contexto inclusivo, e como a pessoa com deficiência era vista e/ou "tratado" em determinados momentos da história, apresenta-se uma reflexão acerca da importância e atenção que essa população precisa e deve ter atualmente, que é a garantia de seus direitos assistidos, sendo assim, o papel da educação e da sociedade de um modo geral, é de assumir uma postura realmente inclusiva.

As informações sobre a relação entre a sociedade e a pessoa com deficiência, na Antiguidade em Roma e na Grécia Antiga, praticamente não dispõe de dados objetivos.

Algumas passagens encontradas na literatura da época e na bíblia permitem analisar a sua natureza e procedimentos. Havia dois agrupamentos sociais: a nobreza (senhores que detinham o poder social, político e econômico,) e o populacho (considerados sub-humanos, dependentes economicamente e propriedade dos nobres). Nesse período, o "valor" de um homem estava vinculado de acordo com os preceitos da nobreza, tal valor era baseado nas características pessoais ou na "utilidade" que o indivíduo poderia oferecer, dessa forma, a "pessoa diferente", era praticamente exterminada por meio do abandono (ARANHA, 2005, grifos nossos).

Nota-se nesse contexto, que a pessoa deficiente, era excluída em razão da sua deficiência, associada a uma "ineficiência", pois, não seria "produtiva" para a nobreza. Assim, nada podia ser feito, e só restava a aceitação dessa condição.

Ainda na Antiguidade, a Bíblia menciona "o diferente" ao cego, ao manco e ao leproso, como sendo pedintes ou rejeitados, vistos através do medo que "a doença" representava, e também, amaldiçoados pelos deuses. Quanto às pessoas com "retardos mentais", serviam-se, de acordo com a literatura antiga, 
de bobo ou palhaço para a diversão dos senhores e de seus hóspedes (ARANHA, 2005, grifos nossos).

Já no Cristianismo, através do fortalecimento da Igreja Católica, começou a surgir no cenário político um novo segmento: o clero. Assim como na Antiguidade, restava ao povo o trabalho, e, ao clero e a nobreza, o enriquecimento e o poder. As pessoas doentes, defeituosas e/ ou mentalmente afetadas não podiam ser exterminadas, porém, dependiam da caridade humana. Assim como ocorria na Antiguidade, a pessoa "diferente" servia como fonte de diversão e material de exposição (ARANHA, 2005, grifos nossos).

Ao longo de cinco séculos, a partir do século XII, temos a Inquisição Católica e a Reforma Protestante, onde o poder exercido pela lgreja foi se expandindo, e consequentemente, gerando contradições entre o discurso religioso e as ações por parte do clero, consideradas abusivas e resultando em opiniões divergentes dentro da própria igreja e fora dela também. Nesse panorama estabelecido, o poder exercido Igreja passou a ficar ameaçado, desencadeando um dos piores momentos da história, onde, qualquer suspeita de posicionamento contrário à igreja, era fortemente condenado sob forma de perseguição ou extermínio, inclusive, até a morte pela fogueira. Constam em documentos da Igreja que as pessoas com deficiência, principalmente a deficiência mental, também representavam uma ameaça contra a Igreja. Se na Antiguidade a pessoa deficiente era esquecida e praticamente "não existia", no período medieval, a questão era talvez, pior, pois no plano da metafísica ${ }^{3}$, de natureza religiosa, a pessoa com deficiência era considerada "demoníaca" (ARANHA, 2005, grifos nossos).

Após o período em que a igreja exerceu sua influência, desencadeia na história, a Revolução Burguesa, responsável pela queda do poder religioso. A Revolução Burguesa foi responsável também, pela implantação de uma nova forma de produção: o capitalismo mercantil, que foi a primeira forma de capitalismo ${ }^{4}$. Nesse período da história, a autora menciona a pessoa com deficiência, ao esclarecer um início de novas ideias, relacionando a deficiência à natureza orgânica, fruto de causas naturais, onde passou a ser tratada também por meio da alquimia, da magia e da astrologia, métodos da incipiente medicina. Já no século XVII, novos avanços na medicina, elucidaram a tese da organicidade, corroborando para o entendimento da deficiência, como um processo natural. A tese da organicidade favoreceu o tratamento das pessoas com deficiência, juntamente com a tese do desenvolvimento por meio da estimulação, ainda que lentamente, para ações de ensino, a partir do século XVIII. (ARANHA, 2005, grifos da autora).

Temos até aqui, uma breve exposição acerca do "tratamento" dado às pessoas com deficiência, marcadas por uma nítida exclusão. Atualmente, as pessoas com deficiência possuem seus direitos garantidos, mediante a uma política nacional, leis e outros documentos nacionais e internacionais. No âmbito

\footnotetext{
${ }^{3} \mathrm{O}$ estado metafísico tem, segundo Comte, outros pontos de contato com o teológico. Ambos tendem à procura de soluções absolutas para os problemas do homem: a metafísica, tanto quanto a teologia, procura explicar a "natureza íntima" das coisas, sua origem e destino últimos, bem como a maneira pela qual são produzidas (COMTE, 1978, p.18, grifos do autor).

4 Iniciou-se, nesse contexto, a formação dos estados modernos, os quais passaram a funcionar com uma nova divisão social do trabalho: os donos dos meios de produção e os operários, os quais passaram a viver com a venda de sua força de trabalho. (ARANHA, 2005, p.12)
} 
escolar, esse "resgate" de direitos até então antes não vivenciados, passa a exercer uma fundamental importância para mudanças significativas, favorecendo e efetivando uma educação inclusiva. A respeito da importância de tais direitos:

Ao longo dessa trajetória, verificou-se a necessidade de se reestruturar os sistemas de ensino, que devem organizarse para dar respostas às necessidades educacionais de todos os alunos. O caminho foi longo, mas aos poucos está surgindo uma nova mentalidade, cujos resultados deverão ser alcançados pelo esforço de todos, no reconhecimento dos direitos dos cidadãos. O principal direito refere-se à preservação da dignidade e à busca da identidade como cidadãos. Esse direito pode ser alcançado por meio da implementação da política nacional de educação especial. Existe uma dívida social a ser resgatada. (BRASIL, 2004, p. 324 , grifos nossos).

\title{
2 A Educação especial na perspectiva da educação inclusiva
}

A Declaração Universal dos Direitos Humanos, adotada e proclamada pela Assembleia Geral das Nações Unidas em 1948, afirma em seu Artigo 1, que: "Todas os seres humanos nascem livres e iguais em dignidade e direitos. São dotados de razão e consciência e devem agir em relação uns aos outros com espírito de fraternidade" (BRASIL, 1998, grifos nossos).

SÁNCHEZ (2005) defende a ideia de que a educação inclusiva é acima de tudo uma questão de direitos humanos, acreditando que não se pode segregar nenhuma pessoa em razão da sua deficiência, de sua dificuldade de aprendizagem, gênero ou se a pessoa pertencer a uma minoria étnica, o que iria contra os direitos humanos. A autora exemplifica que a educação inclusiva é uma atitude, representa valores e crenças, não sendo apenas uma ação, e sim, um conjunto de ações. A autora ainda especifica que:

\begin{abstract}
A filosofia da inclusão defende uma educação eficaz para "todos", sustentada em que as escolas, enquanto comunidades educativas devem satisfazer as necessidades de todos os alunos, sejam quais forem as suas características pessoais, psicológicas ou sociais (com independência de ter ou não deficiência). (SÁNCHEZ, 2005, p. 7, grifos nossos).
\end{abstract}

A Educação em Direitos Humanos através de suas diretrizes nacionais nos orienta acerca do ambiente de aprendizagem:

A escola, ou qualquer ambiente de aprendizagem, é o espaço de convivência inicial do ser humano em formação, bem como uma atmosfera de convivência para os que buscam um objetivo em comum, que é a instrução. É muito importante que esse ambiente possa formar cidadãos inspirados no respeito ao próximo, na aceitação das diferenças. (BRASIL, 2013, p. 30, grifos nossos). 
A Política Nacional da Educação Especial na Perspectiva da Educação Inclusiva evidencia a importância de um novo direcionamento no âmbito educacional fundamentado nos direitos humanos. Tal política nos afirma que:

O movimento mundial pela inclusão é uma ação política, cultural, social e pedagógica, desencadeada em defesa do direito de todos os alunos de estarem juntos, aprendendo e participando, sem nenhum tipo de discriminação. A educação inclusiva constitui um paradigma educacional fundamentado na concepção de direitos humanos, que conjuga igualdade e diferença como valores indissociáveis, e que avança em relação à ideia de equidade formal ao contextualizar as circunstâncias históricas da produção da exclusão dentro e fora da escola. (BRASIL, 2008, p. 5).

A Educação Especial através da Educação Inclusiva visa melhorias no sistema educacional em geral, ao favorecer o acesso e permanência de todos os estudantes, dentre eles, aqueles que possuem algum tipo de deficiência. Abaixo segue um trecho que orienta os sistemas de ensino com vistas à inclusão:

[...] o direito de participar nos espaços e processos comuns de ensino e aprendizagem realizados pela escola está previsto na legislação e nas políticas educacionais. A Constituição da República, quando adota como princípio a "igualdade de condições para o acesso e permanência na escola", compreendido como efetivação do objetivo republicano de "promover o bem de todos, sem preconceito de origem, raça, sexo, cor, idade e quaisquer outras formas de discriminação", prevê uma sociedade com escolas abertas a todos. (BRASIL, 2004, p. 9, grifos do documento).

A segregação acabava gerando o preconceito com relação aos estudantes que não "apresentavam padrões de normalidade", ao eximir a responsabilidade da escola e consequentemente, o favorecimento de maiores avanços nos estudos acerca dessa população, que poderiam visualizar mudanças significativas no campo da educação. A respeito do preconceito vivenciado:

Na tentativa de eliminar os preconceitos e de integrar os alunos portadores de deficiências nas escolas comuns do ensino regular, surgiu o movimento de integração escolar. Esse movimento caracterizou-se, de início, pela utilização das classes especiais (integração parcial) na "preparação" do aluno para a "integração total" na classe comum. Ocorria, com frequência, o encaminhamento indevido de alunos para as classes especiais e, consequentemente, a rotulação a que eram submetidos. (BRASIL, 2004, p. 323, grifos do documento). 
As escolas e classes especiais "favoreceram" fortemente para a exclusão e preconceito com relação ao aluno com deficiência, nesse sentido:

\begin{abstract}
Um longo caminho foi percorrido entre a exclusão e a inclusão escolar e social. Até recentemente, a teoria e a prática dominantes relativas ao atendimento às necessidades educacionais especiais de crianças, jovens e adultos, definiam a organização de escolas e de classes especiais, separando essa população dos demais alunos. Nem sempre, mas em muitos casos, a escola especial desenvolvia-se em regime residencial e, consequentemente, a criança, o adolescente e o jovem eram afastados da família e da sociedade. Esse procedimento conduzia, invariavelmente, a um aprofundamento maior do preconceito. (BRASIL, 2004, p. 323).
\end{abstract}

Atualmente, a legislação brasileira orienta os estabelecimentos de ensino para atender os alunos com necessidades educacionais especiais "preferencialmente" em classes comuns das escolas, em todos os níveis, etapas e modalidades de educação e ensino (BRASIL, 2004, grifos nossos). A LDB 9.394/96, art. 59, evidencia que os sistemas de ensino assegurarão aos estudantes com deficiência, transtornos globais do desenvolvimento e altas habilidades ou superdotação:

I - currículos, métodos, técnicas, recursos educativos e organização específicos, para atender às suas necessidades. Nesse contexto, a LDB propõe uma nova abordagem educacional a ser oferecida a essa população, tornando-se imprescindível que o professor observe e identifique a existência de barreiras que limitem ou impeçam o estudante de participar ativamente do processo escolar.

O Decreto ํㅜ 6.949, de 25 de agosto de 2009, promulga a Convenção Internacional sobre os Direitos das Pessoas com Deficiência, onde estabelece que os Estados Partes assegurem um sistema educacional inclusivo em todos os níveis com os seguintes objetivos, em seu artigo 24, garantindo:

a) O pleno desenvolvimento do potencial humano e do senso de dignidade e autoestima, além do fortalecimento do respeito pelos direitos humanos, pelas liberdades fundamentais e pela diversidade humana;

b) O máximo desenvolvimento possível da personalidade e dos talentos e da criatividade das pessoas com deficiência, assim como de suas habilidades físicas e intelectuais;

c) A participação efetiva das pessoas com deficiência em uma sociedade livre. (BRASIL, 2009, grifos nossos).

\footnotetext{
${ }^{5} \mathrm{Na}$ Lei de Diretrizes e Bases da Educação Nacional, Lei n. 9.394/96, a educação especial é tratada em três artigos de um capítulo específico e está definida como modalidade de ensino destinada aos educandos com necessidades especiais, preferencialmente na rede regular de ensino, com a garantia de que, em virtude de determinadas condições específicas do aluno, podem ser ofertadas modalidades de atendimento fora da classe comum da rede regular. O termo "preferencialmente" abriu a possibilidade de o ensino continuar nas instituições especializadas e não somente na rede regular. (FARIA E LOPES, 2015).
} 
Para a garantia dos direitos de alunos com deficiência, ao acesso nos estabelecimentos de ensino, temos a Lei no 7.853, de 24 de outubro de 1989, que em seu artigo $8^{\circ}$, inciso I, estabelece que é crime "recusar, cobrar valores adicionais, suspender, procrastinar, cancelar ou fazer cessar inscrição de aluno em estabelecimento de ensino de qualquer curso ou grau, público ou privado, em razão de sua deficiência" (BRASIL, 1989, grifos nossos).

\section{Os principais acontecimentos da educação especial no Brasil}

Historicamente a escola se caracterizou pela exclusão de uma grande parcela da população, passando a ser privilégio de um grupo, exclusão apresentada através da segregação e integração no momento que os sistemas de ensino passaram a universalizar o acesso de todos na escola (BRASIL, 2015).

A educação especial, por meio do atendimento educacional especializado, em substituição ao ensino comum, revelou diferentes compreensões, terminologias e modalidades que levaram à criação de instituições especializadas, escolas especiais e classes especiais. No Brasil, o atendimento às pessoas com deficiência, iniciou na época do Império, com a criação de duas instituições: o Imperial Instituto dos Meninos Cegos, em 1854, atual Instituto Benjamin Constant (IBC), e o Instituto dos Surdos Mudos, em 1857, hoje denominado Instituto Nacional da Educação dos Surdos (INES), ambos no Rio de Janeiro.

Posteriormente no século XX, temos no Brasil a fundação do Instituto Pestalozzi (1926), especializada no atendimento às pessoas com deficiência mental; em 1954, é fundada a primeira Associação de Pais e Amigos dos Excepcionais (APAE); e já no ano de 1945, é criado o primeiro atendimento educacional especializado às pessoas com superdotação na Sociedade Pestalozzi, por Helena Antipoff (BRASIL, 2015).

A seguir, um pequeno resumo, com os principais acontecimentos acerca da Educação Especial em nosso país:

I - Resumo de alguns momentos importantes acerca da Educação Especial no Brasil.

\begin{tabular}{|l|l|}
\hline Ano & \multicolumn{1}{c|}{ Fatos marcantes na educação especial } \\
\hline 1961 & $\begin{array}{l}\text { Lei 4.024 de Diretrizes e Bases para a } \\
\text { Educação: }\end{array}$ \\
& $\begin{array}{l}\text { Art. 88- A educação de excepcionais, deve, no que for possível, enquadrar-se } \\
\text { no sistema geral de educação, a fim de integrá-los na comunidade. } \\
\text { Art. 89- Toda iniciativa privada considerada eficiente pelos conselhos estaduais } \\
\text { de educação, e relativa à educação de excepcionais, receberá dos poderes } \\
\text { públicos tratamento especial mediante bolsas de estudo, empréstimos e } \\
\text { subvenções (BRASIL, 1961). }\end{array}$ \\
\hline
\end{tabular}




\begin{tabular}{|c|l|}
\hline 1971 & $\begin{array}{l}\text { Lei } 5.692 \text { de diretrizes e bases para o ensino de 10 } \\
\text { e 2o graus: } \\
\text { Art. 9-- Os alunos que apresentem deficiências físicas ou mentais, os que se } \\
\text { encontrem em atraso considerável quanto à idade regular de matrícula e os } \\
\text { superdotados deverão receber tratamento especial, de acordo com as normas } \\
\text { fixadas pelos competentes Conselhos de Educação (BRASIL, 1971). }\end{array}$ \\
\hline 1988 & $\begin{array}{l}\text { Constituição Federal Brasileira, Art. 208: } \\
\text { III - atendimento educacional especializado aos portadores de } \\
\text { deficiência, preferencialmente na rede regular de ensino (BRASIL, 1998). }\end{array}$ \\
\hline 1990 & $\begin{array}{l}\text { Declaração Mundial sobre Educação para Todos (Conferência de Goten, } \\
\text { Tailândia) } \\
\text { (UNICEF, 1990). }\end{array}$ \\
\hline 1990 & $\begin{array}{l}\text { Lei no 8.069/90: Estatuto da Criança e do Adolescente (ECA) } \\
\text { Art. 54- É dever do Estado assegurar à criança e ao adolescente: } \\
\text { III - atendimento educacional especializado aos portadores de } \\
\text { deficiência, preferencialmente na rede regular de ensino (BRASIL, 1990). }\end{array}$ \\
\hline 1994 & $\begin{array}{l}\text { Declaração de Salamanca na área das necessidades educativas especiais } \\
\text { (Salamanca, } \\
\text { Espanha) (UNESCO, 1994). }\end{array}$ \\
\hline $\mathbf{1 9 9 6}$ & $\begin{array}{l}\text { Lei no 9394/96- Atual Lei de Diretrizes e Bases da Educação Nacional } \\
\text { (LDBEN). } \\
\text { Pela primeira vez no Brasil, uma LDB tem um capítulo reservado à Educação } \\
\text { Especial, cujos detalhamentos são fundamentais (BRASIL, 1996). }\end{array}$ \\
$\begin{array}{l}\text { Resolução CNE/CEB № 2, de 11 de setembro de 2001: } \\
\text { Institui Diretrizes Nacionais para a Educação Especial na Educação Básica } \\
\text { (BRASIL, 2001). }\end{array}$ \\
\hline
\end{tabular}

Quadro organizado pela autora.

A inclusão de alunos com deficiência tem passado por mudanças importantes nas duas últimas décadas. Tais mudanças alcançadas retratam uma nova configuração no que diz respeito ao acesso e permanência desses alunos.

A legislação brasileira, através de documentos internacionais, passou a assumir, significativamente, mudanças no sistema educacional brasileiro, inclusive aos estudantes com deficiência. Nesse panorama, a educação inclusiva elucida a ideia de que:

[...] num contexto onde uma sociedade inclusiva passou a ser considerada um processo de fundamental importância para o desenvolvimento e a manutenção do estado democrático, a educação inclusiva começou a se configurar como parte integrante e essencial desse processo. (MENDES, 2010, p. 103).

O sistema econômico ao qual vivemos, "favorece", a luta pelos direitos humanos, por parte de pessoas em situação econômica desfavorecida, ao clamarem por mudanças, assim temos: 
No Brasil, o sistema capitalista e a ideologia neoliberal têm dado o tom nas relações humanas, mediando interesses conflitantes de pessoas pertencentes a classes sociais distintas, o que tem levado a organização das pessoas em situação menos favorável economicamente em grupos específicos para lutar pela defesa de seus direitos. Entende-se essas organizações como legítimas e necessárias, contudo se essa luta não for unificada, dificilmente acontecerá uma transformação social, podendo acontecer apenas reformas pontuais. (FARIAS; LOPES, 2015).

Destacamos ainda, o Programa Nacional de Direitos Humanos (PNDH), no qual o Brasil visando o fortalecimento da democracia traz como orientação em seu Objetivo estratégico IV: "Promoção e proteção dos direitos das pessoas com deficiência e garantia da acessibilidade igualitária" (BRASIL, 2010), através das seguintes ações:

a) Garantir às pessoas com deficiência igual e efetiva proteção legal contra a discriminação.

b) Garantir salvaguardas apropriadas e efetivas para prevenir abusos a pessoas com deficiência e pessoas idosas.

c) Assegurar o cumprimento do Decreto de Acessibilidade (Decreto $\mathrm{n}^{0}$ 5.296/2004), que garante a acessibilidade pela adequação das vias e passeios públicos, semáforos, mobiliários, habitações, espaços de lazer, transportes, prédios públicos, inclusive instituições de ensino, e outros itens de uso individual e coletivo.

d) Garantir recursos didáticos e pedagógicos para atender às necessidades educativas especiais

e) Disseminar a utilização dos sistemas braile, tadoma, escrita de sinais e libras tátil para inclusão das pessoas com deficiência em todo o sistema de ensino.

f) Instituir e implementar o ensino da Língua Brasileira de Sinais como disciplina curricular facultativa.

g) Propor a regulamentação das profissões relativas à implementação da acessibilidade, tais como: instrutor de Libras, guia-intérprete, tradutor- intérprete, transcritor, revisor e ledor da escrita braile e treinadores de cães-guia.

h) Elaborar relatórios sobre os municípios que possuem frota adaptada para subsidiar 0 processo de monitoramento cumprimento e implementação da legislação de acessibilidade. (BRASIL, 2010).

Carvalho (2005) defende a ideia de que mudanças positivas podem ocorrer "desde que haja vontade política, gerenciamento e lideranças competentes e convencidas, além de professores qualificados em sua formação inicial e continuada" (p. 6).

Através das conquistas relacionadas, quer seja dentro da educação especial ou fora dela, pessoas e ou/ estudantes, com deficiência ou não, 
possuem seus direitos garantidos em leis e assim, sabemos que o direito de TODOS à educação com vistas a inclusão, deve ser consolidada com qualidade.

\section{Considerações finais}

As pessoas com deficiência nos primórdios da história mundial e brasileira foram esquecidas, torturadas, excluídas e vítimas de inúmeros preconceitos, sem o respaldo para o devido tratamento, logo, não possuíam direitos. Atualmente, fruto de suas lutas, possuem a garantia de direitos que devem ser respeitados e garantidos, dentre eles, o direito à educação.

O acesso é garantido em leis, porém, a permanência mediante a uma qualidade de ensino e aprendizagem torna-se fundamental na efetivação da inclusão de alunos com deficiência.

Ao retratarmos um breve histórico no presente estudo, podemos perceber que para chegarmos a ter os direitos estabelecidos para a população público alvo da Educação Especial, um longo caminho de exclusão foi vivenciado. $O$ reconhecimento e efetivação dos direitos conquistados deverão ser assegurados aos alunos com deficiência, e isso propõe ambientes e recursos pedagógicos acessíveis assim como, professores com uma formação acadêmica voltada para atender alunos com deficiência.

Vivenciar os direitos humanos propõe práticas que atuem contra qualquer tipo de exclusão, onde "TODOS" possam usufruir dos seus direitos independente de suas condições físicas, intelectuais, sociais, entre outras. É nesse sentido que a Educação Especial em tempos de inclusão deverá apropriar-se.

\section{Referências}

ARANHA, Maria Salete Fábio. Projeto Escola Viva: garantindo acesso e permanência de todos os alunos na escola: necessidades educacionais especiais dos alunos. Brasília: 2005. Disponível em: < http://portal.mec.gov.br/seesp/arquivos/pdf/visaohistorica.pdf>. Acesso em: 03 mar. 2016.

BRASIL. Constituição da República Federativa do Brasil, de 5 de outubro de 1988. Brasília, 1988. Disponível em:<http://www.planalto.gov.br/ccivil_03/constituicao/constituicao.htm>. Acesso em: 13 set. 2014.

BRASIL. Declaração Universal dos Direitos Humanos. Brasília, 1998. Disponível em:<http://unesdoc.unesco.org/images/0013/001394/139423por.pdf>. Acesso em: 04 mar. 2016

BRASIL. Presidência da República. Decreto no 6.949, de 25 de agosto de 2009. Convenção Internacional sobre os Direitos das Pessoas com Deficiência. Brasília: 2009. Disponível em:<http://www.planalto.gov.br/ccivil_03/_ato2007-

2010/2009/decreto/d6949.htm> Acesso em: 7 fev. $201 \overline{6}$.

BRASIL. Direito à educação: subsídios para a gestão dos sistemas educacionais. Orientações gerais e marcos legais. Brasília: 2004. 353 p. 
BRASIL. Secretaria de Direitos Humanos da Presidência da República. Educação em Direitos Humanos: Diretrizes Nacionais. Coordenação Geral de Educação em SDH/PR, Direitos Humanos, Secretaria Nacional de Promoção e Defesa dos Direitos Humanos - Brasília: 2013.

BRASIL. Presidência da República. Lei no 4.024, de 20 de dezembro de 1961. Fixa as Diretrizes e Bases da Educação Nacional. Brasília, 1961. Disponível em:< http://www.planalto.gov.br/ccivil_03/leis/L4024.htm>. Acesso em: 31 out. 2016.

BRASIL. Presidência da República. Lei $\mathbf{n}^{0}$ 5.692, de 11 de agosto de 1971. Fixa Diretrizes e Bases para o ensino de $1^{\circ}$ e $2^{\circ}$ graus, e dá outras providências. Brasília: 1971. Disponível em: <https://www.planalto.gov.br/ccivil_03/Leis/L5692.htm>. Acesso em: 31 out. 2016.

BRASIL. Presidência da República. Lei no 7.853, de 24 de outubro de 1989. Dispõe sobre o apoio às pessoas portadoras de deficiência, sua integração social, sobre a Coordenadoria Nacional para Integração da Pessoa Portadora de Deficiência. Brasília, 1989. Disponível em: <http://www.planalto.gov.br/ccivil_03/leis/L7853.htm>. Acesso em: 7 fev.2016.

BRASIL. Presidência da República. Lei no 8.069, de 13 de julho de 1990. Dispõe sobre o Estatuto da Criança e do Adolescente e de outras providências. Brasília,

1990. Disponível em:

$<$ http://www.planalto.gov.br/ccivil 03/leis//8069compilado.htm>.Acesso ${ }^{-}$em: 23 out.2016.

BRASIL. Presidência Da República. Lei № 8.069, de 13 de julho de 1990. Dispõe sobre o Estatuto da Criança e do Adolescente e dá outras rovidências. Brasília, 1990.

BRASIL. Presidência da República. Lei no 9.394, de 20 de dezembro de 1996.

Brasília, 1996. Disponível em:<www.planalto.gov.br/ccivil_03/leis/l9394.htm>. Acesso em: 13 set. 2014.

BRASIL. Orientações para implementação da Política de Educação Especial na Perspectiva da Educação Inclusiva. Brasília, 2015. Disponível em:< http://portal.mec.gov.br/index.php?option=com_docman\&view=download\&alias $=17237$ - secadi-documento-subsidiario-2015\&category_slug=marco-2015-pdf\&ltemid=30192>. Acesso em: 23 out. 2016.

BRASIL. Política Nacional da Educação Especial na Perspectiva da Educação Inclusiva. Brasília, 2008. Disponível em:< portal.mec.gov.br/arquivos/pdf/politicaeducespecial.pdf >. Acesso em: 20 jan. 2016.

BRASIL. Resolução CNE/CEB № 2, de 11 de setembro de 2001. Institui as Diretrizes Nacionais para a Educação Especial na Educação Básica. Brasília, 2001. Disponível em: < http://portal.mec.gov.br/cne/arquivos/pdf/CEB0201.pdf >. Acesso em: 23 jun. 2015.

BRASIL. Secretaria de Direitos Humanos da Presidência da República. Programa Nacional de Direitos Humanos (PNDH-3) / Secretaria Especial dos Direitos Humanos da Presidência da República. Brasília: SEDH/PR, 2010.

CARVALHO, Rosita Edler. Educação Inclusiva: do que estamos falando? Revista Educação Especial, n. 26, 2005. Disponível em:< http://cascavel.cpd.ufsm.br/revistas/ojs-2.2.2/index.php/educacaoespecial/article /view/4395/2569>Acesso em: 11 fev. 2016.

COMTE, Auguste. Coleção: Os Pensadores. São Paulo: Abril Cultural, 1978. Disponível em: 
<https://cesarmangolin.files.wordpress.com/2010/02/colecao_os_pensadores_auguste_com te_-_obra_e_vida.pdf >. Acesso em: 02 fev. 2016.

FARIAS, Roseane Rabelo Souza; LOPES, Thais Andrea Carvalho de Figueirêdo. As Pessoas com Deficiência no Contexto da Educação Escolar Brasileira. Revista HISTEDBR. On-line, Campinas, ํㅡ 65, 2015. Disponível em:< https://www.fe.unicamp.br/revistas/ged/histedbr/article/view/7359/6176>. Acesso em: 21 fev. 2016

MANDEL, Ernest. O Capitalismo. Enciclopédia Universalis, 1981. Disponível em: <https://www.marxists.org/portugues/mandel/1981/mes/capitalismo.htm.> Acesso em: 02 mar. 2016.

MENDES, Enicéia Gonçalves. Breve histórico da educação especial no Brasil. Revista Educación y Pedagogía, v. 22, n. 57, 2011. Disponível em:

$<$ https://aprendeenlinea.udea.edu.co/revistas/index.php/revistaeyp/article/view/9842/90 41>. Acesso em: 01 fev. 2016.

SÁNCHEZ, Pilar Arnaiz. A Educação Inclusiva: um meio de construir escolas para todos no século XXI. In: Inclusão - Revista da Educação Especial. Brasília, 2005. Disponível em:< http://portal.mec.gov.br/seesp/arquivos/pdf/revistainclusao1.pdf>. Acesso em: 13 fev. 2016.

UNESCO. Declaração de Salamanca e enquadramento da acção.

Salamanca/Espanha: 1994. Disponível em:

<http://redeinclusao.web.ua.pt/docstation/com_docstation/19/fl_9.pdf>. Acesso em: 31 out. 2016.

UNICEF. Declaração Mundial sobre Educação para Todos: plano de ação para satisfazer as necessidades básicas de aprendizagem. Jomtien/Tailândia, 1990. Disponível em: <http://www.unicef.org/brazil/pt/resources_10230.html.> Acesso em: 31 out. 2016. 